\title{
EL FLORECIMIENTO HUMANO EN CLAVE NEOARISTOTÉLICA
}

\author{
THE HUMAN FLOURISHING IN NEO-ARISTOTELIAN KEY
}

\author{
Jorge Maximiliano Loria \\ (Universidad Nacional de Mar del Plata) \\ maxiloria@yahoo.com.ar
}

Recibido: 30/12/2019

Aprobado: 12/01/2020

\begin{abstract}
RESUMEN
El presente artículo persigue un objetivo preciso y acotado: describir de manera detallada y defender- la concepción macintyreana del florecimiento humano tal como ella ha sido expuesta en su último libro (2016). Para este propósito será preciso hacer un rodeo teórico dedicando unas páginas a presentar las concepciones de lo bueno y el bien que destacan tanto desde una perspectiva pre-filosófica como también desde la posición expresivista actualmente predominante en la filosofía moral. En su conjunto, la argumentación pone de manifiesto la continuidad del pensamiento de nuestro autor, especialmente a partir de la publicación de Tras la Virtud (1981). La obra de MacIntyre puede ser concebida como un extenso combate cultural contra el emotivismo; como una pugna, prolongada en el tiempo, por intentar que la tradición neoaristotélica pueda abrirse nuevamente paso en nuestra sociedad. Todo conduce a la comprensión del siguiente principio: no hay florecimiento humano posible sin el cultivo de aquellas cualidades de carácter y de entendimiento que nos permitan alcanzar los auténticos bienes de nuestra naturaleza.
\end{abstract}

Palabras clave: lo bueno y el bien; florecimiento; expresivismo; neoaristotelismo.

\section{ABSTRACT}

This article pursues a precise and limited objective: to describe in detail -and defend- the macintyrean conception of human flourishing as it has been exposed in her last book (2016). For this purpose, it will be necessary to make a theoretical detour by dedicating a few pages to present the conceptions of the good and the good that stand out both from a pre-philosophical perspective and also from the currently predominant expressionist position in moral philosophy. As a whole, the argument highlights the continuity of our author's thinking, especially after the publication of After Virtue (1981). MacIntyre's work can be conceived as an extensive cultural fight against emotivism; as a struggle, prolonged in time, for trying to make the neo-Aristotelian tradition open again in our society. Everything leads to the understanding of the following principle: there is no human flowering possible without the cultivation of those qualities of character and understanding that allow us to reach the true goods of our nature.

Keywords: good and good; flowering; expressivism; neoristotelianism. 


\section{Lo bueno y el bien: una aproximación pre-filosófica:}

En su libro Ética en los conflictos de la Modernidad. Sobre el deseo, el razonamiento práctico y la narrativa (Rialp, 2017) MacIntyre se embarca en una indagación sobre lo bueno y el bien, destacando los desacuerdos culturales y filosóficos que acontecen en torno a lo que haya que llamar bueno y por qué. Movido por el propósito de lograr una mejor comprensión de estas discrepancias el autor despliega un primer análisis de estas nociones sin adentrarse todavía en las disputas más "técnicas" propias de las diversas escuelas filosóficas.

MacIntyre se pregunta entonces si la comprensión ordinaria de la noción de bien puede poner de manifiesto alguna unidad subyacente a los distintos usos de bueno. Su respuesta destaca que una primera caracterización -"vaga"- de este concepto podría ser:

... decir de algo que es un buen algo es decir que, si quieres o necesitas algo por las razones por las que las cosas de ese tipo [...] son característicamente deseadas o requeridas, entonces ese particular algo colmará tus deseos o tu necesidad (MacIntyre, 2017: 41)

Pero este primer esbozo sobre las nociones de lo bueno y el bien deja abierta al menos dos cuestiones. La primera se relaciona con las discrepancias sobre qué es lo que hace que esto o aquello sea bueno, es decir, apetecible, en su clase. Los padres, por ejemplo, suelen desear una buena educación para sus hijos y, al optar por una escuela determinada, lo hacen estando convencidos de que el establecimiento que eligen colmará sus requerimientos. Sucede entonces que una familia adhiere a un colegio confesional y otra asume una educación laica. Ambas están convencidas de que han elegido una buena educación, pero discrepan, precisamente, en qué es lo que otorga la bondad a tal cosa. La segunda cuestión pone de manifiesto que cuando alguien sostiene que algo es bueno es su tipo, esto no necesariamente implica un elogio $u$ aprobación moral sobre la cosa. Es usual decir que tal o cual persona es buena haciendo "negocios" dando a entender que sus transacciones son eficaces para obtener recursos económicos pero que, a su vez, son éticamente reprochables. No hablamos solo de los buenos músicos sino también de los buenos falsificadores (MacIntyre, 2017: 42). En este sentido, uno puede afirmar que es malo ser buen ladrón o que es bueno ser buen amigo.

Por otra parte, una persona puede estar de acuerdo con otra sobre lo bueno, es decir, sobre que esto o aquello es efectivamente un bien. Y, más aun, pueden coincidir sobre qué hace que esto o aquello sea un bien. Aquí se da el caso de que acuerdan en que tienen buenas razones para desear tal o cual cosa y que además las razones por las que juzgan a algo como bueno coinciden (retomando el ejemplo anterior, se diría que consideran que este o aquel colegio es bueno por los mismos motivos). Sin embargo, estas personas pueden no estar de acuerdo sobre cómo ordenar jerárquicamente los diversos tipos de bienes. Se discrepa entonces sobre la prioridad que se otorga a los bienes.

Las discrepancias sobre el orden jerárquico de los bienes conllevan desacuerdos sobre qué proporciona razones suficientes para actuar de un modo en lugar de otro. En este punto MacIntyre propone un ejemplo notorio referido al lugar que diferentes personas pueden dar al placer en sus vidas aun cuando todas ellas puedan considerarlo en sí mismo como algo bueno.

Así, por ejemplo, están aquellos para los que el placer, los placeres sensuales, los placeres estéticos, cuentan muy poco, pues los tienen generalmente por una distracción de los asuntos serios de la vida, y aquellos para los que tales placeres hacen que la vida, aunque solo sea en ese instante $-\mathrm{y}$ sus vidas acaso no sean sino una sucesión de instantes - tenga sentido y propósito. Los primeros renunciarán al placer a cambio de lo que consideran un logro valioso; los últimos renunciarán en determinadas ocasiones, a casi todo si el placer a disfrutar es lo suficientemente grande (MacIntyre, 2017: 44)

Como se dijo, el lugar que ocupa el placer en cada una de estas vidas es diametralmente distinto. Sucederá entonces que los juicios y acciones de cada uno escandalizarán a los otros. A su vez, ambos encontrarán que es difícil comprender al contrario excepto en términos patológicos (MacIntyre, 2017: 44). En síntesis, la modernidad tardía se afinca en la convicción de que no puede haber una única manera racional de jerarquizar los bienes, sino que hay muchas maneras alternativas de ordenarlos; en 
principio, pueden existir tantas formas diversas como individuos. La multiplicidad y heterogeneidad de los bienes humanos es tal que su búsqueda no puede reconciliarse en ningún orden moral único (MacIntyre, 1987: 181).

Hasta aquí nuestro autor se limitó a describir las discrepancias en torno a las nociones de lo bueno y el bien que predominan en la modernidad tardía. Y este conflicto en torno a los bienes (a qué hace que tal o cual cosa sea un bien y sobre cómo ordenar los bienes) parece a todas luces culturalmente insalvable. Lo más paradójico de todo esto es que la mayoría de los hombres no consideran esta situación como una pérdida, sino más bien como una ganancia de la que es preciso enorgullecerse. Como en varias ocasiones repite el autor, este desacuerdo es dignificado en nuestro tiempo con el nombre de pluralismo. Bajo la máscara de la retórica pluralista se esconde la multitud de nuestros conflictos morales (MacIntyre, 1987: 310). Seguidamente, MacIntyre se propone analizar y comparar las posiciones que, acerca de este tema, se proponen en dos corrientes filosóficas, el expresivismo (también conocido como emotivismo) y el neo-aristotelismo, corriente a la que el propio autor suscribe. Ambas tienen sus fuentes últimas en Hume y Aristóteles respectivamente. Aun así, es preciso no "esperar" demasiado de estas nuevas descripciones, puesto que los filósofos morales actualmente predominantes parece que solo ofrecen sus propias discrepancias sobre cómo entender las discrepancias acerca de lo bueno (MacIntyre, 2017: 45)

\section{La postura expresivista sobre lo bueno y el bien:}

En Tras la Virtud MacIntyre describió al emotivismo como teoría filosófica especialmente con el propósito de ocuparse de las consecuencias culturales que siguieron al predominio de esta posición: vivimos en una cultura predominantemente emotivista. Y aunque no sea algo plenamente consciente, muchos de nuestros juicios prácticos y modos de conducta presuponen la verdad del emotivismo (MacIntyre, 1987: 39). Por ejemplo, si alguien dice frente a otros: "esto está mal", quienes están a su lado al unísono responden: "esto está mal para vos", lo cual, no deja de ser en cierta medida paradójico, pues se considera universalmente verdadero (y políticamente correcto) sostener que no existen acciones buenas o malas en sentido absoluto; lo bueno y lo malo son siempre relativos a un sujeto cuyo juicio además puede modificarse sustancialmente si se modifican los contextos.

Para nuestro autor, Charles L. Stevenson ha sido el expositor más importante de esta teoría. Él mismo recuerda que la exposición clásica del emotivismo se encuentra en el libro Ética y lenguaje (1945) del propio Stevenson ${ }^{6}$. Los expresivistas se ocuparon fundamentalmente de las afirmaciones evaluativas y normativas, de aquí que sus análisis acerca de lo bueno y el bien hay que ubicarlos en esta perspectiva más amplia de interpretación (MacIntyre 2017, p. 46). Según Stevenson existen tres tipos de oraciones afirmativas: a) las oraciones que exponen hechos, las cuales describen como es el mundo y tienen valor de verdad, es decir, son verdaderas o falsas; b) las oraciones que expresan actitudes de aprobación y desaprobación hacia tales hechos (actitudes evaluativas) que tienen un significado emotivo y no son ni verdaderas ni falsas; c) las oraciones que son tanto descriptivas como emotivas (MacIntyre, 2017: 47). Los juicios referidos a la bondad pertenecen al tercer grupo y, tal como se había señalado ya en Tras la Virtud, el significado de estas oraciones sería el siguiente: cuando una persona afirma «esto es bueno» estaría diciendo: «yo apruebo esto, hazlo tú también». Como puede observarse, en esta afirmación se concentran tanto la función del juicio evaluativo, entendido como una expresión de actitudes subjetivas, como también el propósito de este tipo de juicio, o sea, tratar de influir sobre las actitudes de aquel que escucha (MacIntyre, 1987: 27).

Pero según MacIntyre, esta aproximación no hace justicia a los diferentes modos en que pueden combinarse el significado emotivo y descriptivo en las oraciones, aunque cabe destacar que Stevenson

\footnotetext{
${ }^{6}$ Hay una edición española de este libro: Paidós (1984). Sobre el emotivismo ético puede consultarse también la síntesis que Ramis Barceló realiza en su libro sobre MacIntyre (2012: 65-71). Asimismo, remito existe el libro Ethical Emotivism específicamente dedicado al tema (Satris, 1987).
} 
considera que este tipo de oraciones siempre pueden ser analizadas de tal modo que el componente emotivo se distinga de aquel que se refiere a los hechos. A su vez, los desacuerdos sobre hechos siempre pueden resolverse apelando a la experiencia. En cambio, las discrepancias de postura (las referidas a la aprobación o desaprobación) solamente pueden ser resueltas si una de las partes del desacuerdo es persuadida para que cambie su postura; como se dijo, el propósito principal de las declaraciones evaluativas es persuadir a los otros (MacIntyre, 2017: 47). Se trata, por tanto, de una finalidad esencialmente manipuladora. El expresivismo (emotivismo) entraña dejar a un lado cualquier distinción entre relaciones sociales manipuladoras y no manipuladoras.

Una relación manipuladora es un tipo de vínculo no informado por la moral, en el cual se utiliza a los demás como un instrumento para la obtención de los propios fines. Contrariamente, en una relación no manipuladora, o sea, una relación de carácter moral, se trata a los otros como fines en sí mismos. Por lo tanto, se les ofrecen razones para que actúen de un modo en lugar de otro y, además, se les brinda la posibilidad de evaluar dichas razones de modo que las sometan a su propio juicio prudencial (MacIntyre, 1987: 40-41).

Una primera crítica que el autor propone para esta teoría emotivista acerca de los juicios valorativos radica en que su visión entra en conflicto con algunos de nuestros usos lingüísticos habituales referidos a las nociones de verdadero y de hecho, como, por ejemplo, cuando afirmamos que «es un hecho que es malo gozar de la desgracia ajena», o bien que «es verdad que el crecimiento del desempleo (un hecho determinado) es malo» (MacIntyre, 2017: 47). Otras críticas pueden expresarse a la postura moral expresivista, sin embargo, concluye MacIntyre:

\footnotetext{
... no solo no ha surgido hasta el momento ningún argumento que refute al expresivismo, al menos ninguno que un expresivista honesto y filosóficamente sofisticado encontraría decisivo, sino que además hay pocas perspectivas o ninguna de que se hile un argumento así (MacIntyre, 2017: 51).
}

Seguidamente MacIntyre esgrime -ahora sí- una breve descripción de cómo han representado los expresivistas el bien y «lo bueno». En relación con esto despliega -en primer término- la postura de Alan Gibbard, el cual sostiene que las cosas que llamamos buenas son deseables, y que la mejor entre dos cosas es aquella que resulta preferible. Y lo preferible es -para Gibbard- aquello que sería razonable preferir. Así, cuando alguien sostiene que algo es racionalmente preferible (bueno) está expresando un cierto estado mental, además de su lealtad a ciertas normas y valores que, probablemente, nunca se haya explicitado a sí mismo. En este sentido, nuestros juicios acerca de lo bueno tienen un cierto carácter impersonal, pues a partir de ellos no estamos expresando nuestras preferencias o compromisos normativos meramente individuales: la bondad es lo que nuestros propósitos racionales tienen en común con los demás seres humanos, es lo que todo el mundo tiene alguna razón para promover. Pues existe un consenso bastante extendido, un acuerdo subyacente, acerca de qué es racional preferir. Este "consenso" se fundaría, a juicio de Gibbard, en una tesis de carácter naturalista, propia de la evolución biológica, de la historia de nuestro desarrollo evaluativo y normativo que pone de manifiesto nuestra necesidad de aseguranos la cooperación de otros, lo cual ha desembocado en una disposición a responder afirmativamente hacia determinadas preferencias y normas. Pero ha de quedar claro que no hay nada aquí relativo a cómo son en verdad las cosas, se trataría más bien de un cierto consenso evolutivamente alcanzado a causa de nuestra necesidad de convivencia (MacIntyre, 2017: 51-52).

En segundo lugar, MacIntyre analiza la postura de Blackburn quien recuerda que tanto las personas comunes como aquellos que se han consagrado a la reflexión moral se han visto confrontados con la necesidad de escoger entre el impulso de la pasión y los dictámenes de la razón. Pero desde la perspectiva expresivista constituye un error pensar en estos términos.

Y por ello Blackburn ha insistido en que «si planteamos los problemas prácticos en términos de "qué haría yo si fuera razonable" o "lo que una persona razonable haría", no deberíamos pensar que haciéndolo hemos ido más allá del sometimiento de la voluntad al deseo y la pasión. Aquí "razonable" es una [mera] etiqueta... (MacIntyre, 2017: 54). 
Desde Hume hasta Gibbard y Blackburn los expresivistas han sostenido que solamente una concepción expresivista de nuestros juicios evaluativos y normativos nos permite comprender por qué tales juicios nos motivan. MacIntyre propone entonces un ejemplo elocuente sobre la posición emotivista: si yo actúo para aliviar la angustia de alguien que está angustiado, lo que me mueve no es el hecho de su angustia, sino mi postura ante ese hecho, mi conmiseración o deseo de que se me considere compasivo (MacIntyre, 2017: 54).

En síntesis, la postura expresivista sostiene que cuando dos personas discrepan sobre qué es o sería bueno que alguien fuera, hiciera o tuviese, no se trata aquí de discrepancias relativas a algún asunto de hecho, a algo que sea independiente de las posturas o estados psicológicos de quienes no se ponen de acuerdo. Cuando una persona expresa sus preferencias evaluativas da cauce a sus propios estados mentales. En los desacuerdos que conciernen a hechos corrientes o relativos a la ciencia natural una de las partes en disputa está en lo cierto y la otra no, en virtud de cómo ocurrieron las cosas. Para este tipo de desacuerdo se apela a un patrón externo, objetivo e independiente de los sentimientos, intereses, compromisos y posturas de cada uno de nosotros. En torno a hechos no puede entonces haber discrepancias. Pero, desde la óptica expresivista (Stevenson, Gibbard o Blackburn) no hay nada similar a esto en el campo de las discrepancias evaluativas. Cuando lo que está en cuestión es un asunto evaluativo o normativo, no cabe apelar a una autoridad externa e independiente de los sentimientos, intereses, compromisos y posturas del agente. Mejor dicho, si un agente apela a un patrón externo, será solo en virtud de su explícito apoyo subjetivo a la autoridad de dicho patrón. Así, el acuerdo acerca de hechos es perfectamente compatible con la discrepancia evaluativa. (MacIntyre, 2017: 55-56).

Aquellos que adhieren al expresivismo suelen creer que el hecho de que las discrepancias sobre juicios de valor no se pueden resolver de la manera en que se saldan las discordancias fácticas es algo que fortalece su propia teoría. Como respuesta a esta convicción culturalmente recurrente MacIntyre concluye lo siguiente. Por un lado, parece innegable que si el expresivismo es verdadero, entonces es cierto que las discrepancias evaluativas son irresolubles. Por otra parte, también es verdad que no se ha proporcionado a los expresivistas argumentos auténticamente sólidos para que cambien de parecer. Sin embargo -sostiene el autor-, no podrá reconocerse la solidez del planteamiento expresivista hasta que no se lo compare con la opción alternativa y filosóficamente incompatible del bien y lo bueno, es decir, con lo que MacIntyre denomina neo-aristotelismo (MacIntyre, 2017: 57-58).

\section{La posición neoaristotélica:}

Este punto de vista rival y alternativo al expresivismo se funda en el concepto de florecimiento ${ }^{7}$ humano. Según MacIntyre, el concepto de realización o florecimiento se torna especialmente problemático cuando se utiliza para referirse a los seres humanos. Pues aquellos que estudian el comportamiento de especies de animales no humanos distinguen sin controversias (existen cánones objetivos para realizar tal distinción) entre individuos y grupos que florecen e individuos y grupos de especies que no logran prosperar. Los miembros de las especies animales requieren un tipo particular de ambiente para florecer, es decir, para desarrollar sus capacidades específicas, para proteger y criar a sus jóvenes, y para alcanzar los fines hacia los cuales están biológicamente dirigidos.

\footnotetext{
${ }^{7}$ El término florecimiento es una noción de especial importancia en la antropología macintyreana. Se trata de un término perfectamente intercambiable con la idea de buen vivir. En efecto: “... el concepto de florecimiento se asemeja a otros conceptos que implican usos del concepto básico de bien («florecer» se traduce como eu zen y bene vivere)" (MacIntyre, 2001: 83). Cabe mencionar también que la equiparación de las nociones de eudaimonia y florecimiento fue propuesta en primer término por J. Cooper con el propósito de intentar superar las discrepancias teóricas que suscitaba su traducción por felicidad. Autores pertenecientes a la tradición neo-aristotélica y neotomista la han asumido. Entre los primeros, cabe mencionar a M. Nussbaum. De los seguidores del Aquinate puede ponerse como ejemplo a J. Maritain. Basten, a modo de ejemplo, dos breves referencias: "En una teoría ética eudaimonista, la pregunta central que se plantea una persona es «¿Cómo ha de vivir el ser humano?». La respuesta a tal interrogante es la concepción que esa persona detente de la eudaimonía o florecimiento humano, en el sentido de qué entiende por una vida humana plena” (Nussbaum, 2008: 54). Y también: "La sociedad política está destinada a desarrollar condiciones de vida común que, mientras procuran en primer lugar el bien, el vigor y la paz del todo, ayudan positivamente a cada persona a la conquista progresiva de esa libertad de expansión, la cual consiste ante todo en el florecimiento de la vida moral y racional...” (Maritain, 1982: 50).
} 
Complementariamente, se conoce de modo certero aquello que es malo para los individuos de cada una de estas diferentes especies: cuáles son sus depredadores, qué enfermedades pueden aquejarlos, etc. Todo esto produce animales incapaces de desarrollar sus capacidades específicas. Como puede observarse, es indispensable caracterizar el saber científico sobre los animales utilizando conceptos tales como bueno y malo y otros términos asociados a estas nociones.

A su vez, aquello que es bueno o malo para un individuo particular depende sobretodo de la especie a la que pertenece (lo que es bueno para los miembros de una especie puede ser un mal para los miembros de otra). Asimismo -y esto es precisamente lo relevante para la presente argumentación-, cuando se afirma que a esta particular especie animal le está yendo bien o mal en su ambiente particular, este juicio no es en absoluto expresivo de nuestros sentimientos, actitudes o estados psicológicos. Su verdad o falsedad se determina apelando a criterios que son independientes del observador. (MacIntyre, 2017: 58-59). En síntesis, para las especies animales nadie parece poner en duda la validez universal del siguiente principio: para cada tipo de seres existe un determinado tipo de bienes (determinables de manera objetiva) que posibilitan su florecimiento.

Ahora bien, desde la perspectiva neoaristotélica, tal y como acontece con las especies animales, lo mismo sucede con los seres humanos. Acerca de los animales humanos podemos decir, al igual que con las demás especies, que ser, hacer o tener tal o cual cosa, es bueno o malo, significando con ello que esas cosas conducen, o fracasan en conducir, hacia su florecimiento. Así, cuando se comparan diversos cursos de acción posible, el criterio de discernimiento es el siguiente: cuán lejos podría, cada uno de estos caminos alternativos, contribuir a nuestro florecimiento. Puede reconocerse entonces un cierto criterio para el ejercicio de la racionalidad práctica, es decir, una "piedra de toque" para discernir la conveniencia o no de una acción particular: elijo esta y no otra acción buena porque, dadas las particulares circunstancias en las que ahora me encuentro, ella es la que mejor puede predisponerme (no solamente a mí sino también a todos aquellos que viven conmigo y de los que, de algún modo, soy ineludiblemente responsable) a la conquista de la realización humana ${ }^{8}$.

Resulta evidente que nuestros juicios prácticos cotidianos acerca de lo bueno y de lo malo presuponen una cierta visión, más o menos consciente e incipiente sobre lo que es el florecimiento humano. Si elijo comprar un libro de filosofía en lugar de unas zapatillas lujosas es debido a que considero que el cultivo de mi espíritu es más acorde con el florecimiento humano que la aceptación social a la que puedo acceder por el estar calzado a la moda. Así los desacuerdos con otros acerca de qué sería mejor hacer, ser o tener expresan desacuerdos sobre lo que es la realización humana o bien sobre qué es aquello que puede conducir mejor al florecimiento, tanto en sí mismo como en estas particulares circunstancias (MacIntyre, 2017: 59). En efecto:

Como ocurre con los juicios sobre la realización de los miembros de otras especies o el fracaso en la misma, el contraste con el expresivismo es obvio. Los juicios sobre lo que es bueno o mejor para mí, para usted o para nosotros no se consideran expresivos de mi estado mental, el suyo o el de ambos. Y las discrepancias sobre lo que es bueno o mejor ser, hacer o tener han de fijarse apelando a un patrón que es independiente de los sentimientos, intereses, compromisos y posturas de los individuos en cuestión (MacIntyre, 2017: 60).

Ahora bien, si es verdad que todos vivimos bajo la égida de una idea más o menos consciente de lo que significa florecer y también es cierto que solemos creer que dicha concepción se ancla no en nuestros estados mentales subjetivos sino en lo que en realidad somos qua seres humanos; si esto así ocurre, ¿por qué entonces es asimismo evidente que las personas son incapaces de resolver sus desacuerdos sobre lo que significa e implica florecer como seres humanos?, ¿no será acaso cierto que -como afirma el emotivismo- aquello que juzgamos como perteneciente a la naturaleza humana en cuanto tal no es

\footnotetext{
${ }^{8}$ Sin la posibilidad de un verdadero conocimiento del fin último, de aquel bien en el que se encuentra nuestra plenitud, el hombre se encontraría en una cierta situación trágica, dirigido hacia una multitud de bienes finitos, sin que esos bienes pudieran satisfacerlo, y sin criterio objetivo alguno para juzgar su valor (MacIntyre, 1992: 178). Asimismo, Rodríguez Luño confirma esta tesis al sostener que: "Por el momento nos limitamos a señalar, con MacIntyre, que la clave de la actividad de la razón práctica [...] es tener como punto de referencia el conocimiento y el deseo de un fin de valor absoluto" (Rodríguez, 2004: 29).
} 
sino la manifestación de nuestra propia percepción subjetiva de dicha supuesta naturaleza? MacIntyre reconoce que este tipo de preguntas se dirigen directamente al núcleo del problema que enfrenta a expresivistas y aristotélicos. Aun así, antes de continuar el despliegue de su argumentación insiste en una tesis que ya había de algún modo anticipado en Tras la Virtud: la vida buena para el hombre es, al menos en parte, la vida dedicada a buscar la vida buena para el hombre (MacIntyre 1987: 271); o bien, tal y como ahora lo expresa: en el interior del punto de vista aristotélico la investigación racional y los desacuerdos que ella puede generar acerca de lo que es el florecimiento humano es ya, ella misma, una de las marcas de la realización (MacIntyre, 2017: 60).

Seguidamente, MacIntyre se propone profundizar la analogía entre los seres humanos y los animales no humanos. Considera entonces algunas diferencias que juzga sustanciales. El medio ambiente de los animales es algo dado. Por lo general, los animales no racionales florecen dentro de su hábitat particular al que se encuentran satisfactoriamente adaptados. Esta tesis reproduce un tópico de la antropología fillosófica clásica según el cual se afirma que los animales tienen hábitat o mundo circundante mientras que el hombre tiene mundo, es ser en el mundo ${ }^{9}$. Los seres humanos son los únicos que han podido adaptarse a casi cualquier entorno y han transformado estos mismos entornos de manera drástica de modo de adaptarlos a sus necesidades. Y en el curso de cambiar la naturaleza, los hombres se modificaron a sí mismos y -sostiene el autor- desarrollaron el lenguaje como aptitud eminentemente humana. MacIntyre señala aquí cuatro características distintivas del lenguaje humano: i) su estructura sintáctica: ella nos permite preguntarnos acerca de la verdad de nuestras afirmaciones, sobre la validez de nuestras inferencias y la justificación de nuestras conclusiones. Comenzamos a ser reflexivos preguntando y respondiendo tales cosas; ii) acrecienta nuestra capacidad de comunicación; nos permite formular y comunicar complejas y detalladas intenciones, entender respuestas complejas y detalladas por parte de los otros y responder a sus respuestas de una manera que sería imposible sin el lenguaje. Ello posibilita formas de cooperación y asociación distintivamente humanas; iii) la posesión de un lenguaje con diversos tiempos verbales y conectivos lógicos nos permite prever futuros alternativos, fijarnos metas individuales y compartidas y formarnos expectativas sobre nosotros mismos y sobre los demás; iv) la capacidad lingüística nos hace capaces de contar historias acerca de nuestros proyectos, de nuestras empresas heroicas y de nuestros fracasos, historias que representamos y de las cuales podemos aprender (MacIntyre, 2017: 61-62). Se retoma una vez más un rasgo característico de la antropología macintyreana: el hombre, tanto en sus acciones y prácticas como en sus ficciones, es un animal que cuenta historias (MacIntyre, 1987: 266).

MacIntyre señala entonces que la contrapartida de estas capacidades se expresa en el hecho de que las cosas pueden salir mal (malograrse) en nuestras vidas de un modo que no puede darse en los animales no humanos. Está en nuestra naturaleza el tratar de entender, pero podemos malentendernos a nosotros mismos y a los demás; podemos hacer juicios falsos e inferencias inválidas; nuestro pensamiento sobre el futuro puede ser ilusorio o temeroso; nuestras historias pueden ser distorsiones o distracciones de la realidad. Pero otra capacidad distintivamente humana es la capacidad de identificar y de aprender de nuestros errores. Las capacidades humanas se han desarrollado históricamente de múltiples modos; esta es la causa de la multiplicidad de culturas cada una con su particular modo de entender la condición humana. Cada cultura encarna, a su vez, una concepción distintiva del florecimiento humano expresada fundamentalmente en sus juicios de valor. Es entonces evidente que existen muchos modos incompatibles en los que el florecimiento humano ha sido y es actualmente concebido. Por lo tanto, parecería obvio concluir que no existe casi ningún parecido entre el modo en que pensamos acerca del florecimiento de los animales no humanos y el modo en que pensamos sobre el florecimiento humano. Una vez más: aquellos que estudian a los animales no racionales tienen poca dificultad en ponerse de acuerdo sobre lo que significa florecer para tal o cual especie; en cambio, las perspectivas de arribar a un acuerdo sobre el florecimiento humano son escasas, pues lo que cada uno de nosotros entiende por

\footnotetext{
9 "La diferencia específica entre el animal y el hombre consiste, por tanto, en que aquel tiene entorno y éste tiene mundo [...] Entorno (Unwelt) significa un espacio vital perfectamente limitado [...] Mundo (Welt) significa, por el contrario, un horizonte basto que rompe por definición cualquier limitación precisa y elimina toda fijación, siendo por lo mismo más amplio que el espacio vital inmediato" (Amengual, 2016: 40).
} 
florecimiento humano depende en gran parte de la cultura en la que habita y de los recursos evaluativos que le han sido provistos por dicha cultura (MacIntyre, 2017: 62-63).

No obstante, MacIntyre redobla una vez más la apuesta teórica y sostiene que las consideraciones precedentes invitan a pensar que es posible comprender las nociones de lo bueno el bien en una relación estrecha con la concepción que habla del florecimiento humano, es decir, que puede argumentarse sólidamente a favor de una comprensión neoaristotélica de estas nociones. Estas son las razones que MacIntyre proporciona para justificar esta tesis: i) el grado evidente de disenso entre las culturas -y al interior de estas- en cuanto a qué sea el florecimiento humano se encuentra estrechamente relacionado con el disenso sobre los juicios en relación con lo bueno y malo, sobre qué prioridad hay que dar a los bienes y, más en general, sobre cómo el adjetivo bueno tiene que ser usado. Esto, a mi juicio, pondría de manifiesto que, más allá de los disensos culturales, las nociones de florecimiento humano y las nociones de lo bueno y el bien siempre -como vulgarmente se dice- "van de la mano"; ii) en la mayoría de las culturas se da por sentado que la realización humana consiste justamente en lo que, al respecto, se entiende en dicha civilización. Para los actuales católicos tradicionales el florecimiento humano implica la práctica del culto católico tradicional; para aquellos que asumen la filosofía de vida yogui la realización del hombre consiste en el ejercicio cotidiano del yoga (MacIntyre, 2017: 63-64).

El problema estriba, pues, en identificar una medida que nos permita decidir entre estas posturas rivales. ¿Nos es posible a todos dar un paso atrás para contemplar con perspectiva la versión de la realización humana que está imbricada en nuestra propia cultura y compararla con las visiones rivales de culturas diferentes y con la realidad? (MacIntyre, 2017: 64)

Se trata entonces de encontrar un parámetro que se encuentre por encima de las posturas rivales y alternativas del florecimiento. MacIntyre confía en los recursos teóricos aportados por Aristóteles, pues si bien muchas de sus opiniones reflejaban la cultura aristocrática de su tiempo ${ }^{10}$, también es verdad que su concepción del florecimiento humano se enfrentaba abiertamente con la de la mayoría de sus contemporáneos griegos. Aristóteles utilizó los recursos de su cultura para ir más allá de su cultura, evaluando críticamente sus prácticas e instituciones mediante patrones que él presentó cómo merecedores de ser compartidos por cualquiera que razonase adecuadamente. En este sentido, MacIntyre propone cuatro componentes del concepto aristotélico de florecimiento: i) supone la identificación de la totalidad de las capacidades humanas: físicas, emocionales, racionales, políticas, morales y estéticas. Para entender el florecimiento es preciso reconocer la totalidad de nuestras facultades y los diversos hábitos que, a modo de segunda naturaleza, pueden sobreañadirse a ellas; ii) exige el reconocimiento de nuestra capacidad diferencial, es decir, de la facultad que nos posibilita el ejercicio de aquella función (ergon) que nos diferencia específicamente del resto de los animales. El entendimiento o nous, con sus dimensiones teórica y práctica, se pone especialmente de manifiesto en el lenguaje; iii) las habilidades específicamente humanas nos permiten asociamos cooperativamente con otros de formas no abiertas a los animales no humanos. Por naturaleza somos animales tanto racionales como políticos y alcanzamos nuestra estatura humana en, y a través de, las relaciones políticas; iv) si nuestra educación ha sido adecuada, si se nos ha iniciado en la práctica de las virtudes, esta pedagogía nos dirige hacia los auténticos bienes de nuestra naturaleza. Se realiza así el desarrollo de nuestras capacidades y, consiguientemente,-al menos en parte- nuestro florecimiento, de modo que se nos pueda llamar justamente eudaimon (MacIntyre, 2017: 64-65). Las notas previamente expresadas pueden sintetizarse adecuadamente en cuatro nociones ya familiares para nuestro autor: biología metafísica; racionalidad (teórica y práctica), vida comunitaria y virtudes.

Aristóteles ha de apelar a estos cuatro aspectos [...] poder explicar en qué consiste que un agente humano se realice, que funcione bien. Porque su pensamiento central es que realizarse se traduce en funcionar

\footnotetext{
${ }^{10}$ Una breve cita de E. Berti en su libro dedicado a la Política de Aristóteles basta para confirmar esta tesis: "Ahora centrémonos en que Aristóteles [...] deplora que los bárbaros sitúen al mismo nivel a la mujer y al esclavo, hecho que atribuye a la naturaleza de esclavos que poseen todos los bárbaros, incapaces de gobernarse a sí mismos, por lo cual concluye que es justo que los griegos dominen a los bárbaros. Evidentemente, se trata de ideas machistas, esclavistas y racistas que eran lugares comunes en tiempos de Aristóteles" (Berti, 2012: 28).
} 
bien11. Las máquinas funcionan bien o mal. Los animales no humanos funcionan bien o mal. Y lo mismo que cabe decir [...] los agentes humanos y las sociedades humanas: funcionan bien o mal (MacIntyre, 2017: 65-66).

Se manifiesta aquí, una vez más, el agudo contraste con la postura expresivista (emotivista): es una cuestión de hecho -y no de apreciación subjetiva- el poder establecer si un hombre es o no un buen ser humano, el poder juzgar si una persona "funciona bien" o no. Parte de esta tesis había sido ya también abordada en Tras la Virtud al hablar de la persona como investida de papeles sociales. Puesto que cada ser humano tiene que cumplir con las exigencias de unos papeles sociales específicos (de padre o hijo; de artesano o comerciante; de maestro en artes o religioso) con deberes y derechos claramente definidos, se dispone entonces de criterios objetivos, susceptibles de ser fácticamente contrastados, para determinar la calidad de un agente moral determinado; siempre es posible llamar a alguien bueno o malo, justo o injusto, pues puede verificarse si cumple o no con sus obligaciones sociales. MacIntyre propone una analogía esclarecedora -aun cuando él mismo la califica de peligrosa en caso de ser malinterpretada- entre la concepción aristotélica de la vida y el juego del ajedrez. Dado cómo son las cosas en el ajedrez, es una cuestión de hecho si una persona es o no un buen jugador; por ejemplo, un jugador excelente es capaz de tramar estrategias eficaces para la victoria. De manera semejante, para la tradición moral aristotélica es también algo manifiesto si una persona se encuentra o no encaminada en la senda del florecimiento.

Permítaseme usar una analogía peligrosa, pero esclarecedora [...] El juego de ajedrez presupone, y en realidad está parcialmente constituido por, el acuerdo sobre cómo jugar al ajedrez. Dentro del vocabulario del ajedrez no tiene sentido decir «ése es el único y solo movimiento que conseguiría dar jaque mate, pero ¿estaría bien hacerlo?». Alguien que diga esto y entienda lo que está diciendo ha debido emplear una noción de «bien» cuya definición es ajena al ajedrez, y alguien debería preguntarle, si lo que se propone es distraerse como un niño más que ganar (MacIntyre, 1987: 160).

Ejercitar virtuosamente los propios roles es una de las formas más eficaces de orientarse hacia la realización humana. En contraposición, detenerse siquiera a "pensar en otra cosa" diferente a lo exigido por las propias funciones, el abrigar la posibilidad de desasirse de las propias e intransferibles responsabilidades comunitarias, es ya una marca de deficiencia moral, una muestra suficiente de carencia en las virtudes; parafraseando al autor, "alguien debería preguntarle a esa persona si lo que quiere es vivir bien o está jugando temerariamente con su vida".

En síntesis: los juicios acerca del funcionamiento de los agentes humanos particulares son factuales y pueden ser objetivamente evaluados, es decir, no son en absoluto expresivos y, en este sentido, son también verdaderos o falsos, dependiendo tan solo de cuáles sean los hechos. No obstante, es a todas luces innegable que los hechos relevantes sobre los seres humanos son bastante más complejos que los hechos relevantes sobre los animales no humanos. Una vez más, la aproximación aristotélica asumida por MacIntyre expresa una idea de lo bueno y el bien que se vincula estrechamente con la noción de florecimiento: si alguien juzga que sería bueno para cierto individuo o grupo ser, hacer o tener esto o lo otro, eso quiere decir que piensa que eso mismo estaría contribuyendo a la realización humana de esta persona o comunidad (MacIntyre, 2017: 66).

Dando un paso más en la argumentación MacIntyre propone la siguiente tesis: en los juicios morales y en las acciones de las personas corrientes de diversas culturas se da cierta noción incipiente de lo que es el florecimiento humano y esta noción es, en su esencia, aristotélica. Asimismo, cuando esta idea que está "debajo" de dichos juicios y acciones discrepa con las tesis aristotélicas, tales agentes yerran

\footnotetext{
${ }^{11}$ Es inevitable no pensar aquí en aquello que he denominado teoría macintyreana de los conceptos funcionales y que fue expuesta por el autor en Tras las virtud. Un concepto funcional es aquel que contiene en su definición el propósito que, según se espera, debe cumplir todo aquello sobre quien recae válidamente dicha noción. Por ejemplo, nuestra idea de reloj contiene la convicción de que este artefacto tiene que indicar acertadamente la hora. En este sentido, MacIntyre sostiene que la noción de hombre era para Aristóteles un concepto funcional. Esto significa que en la idea misma de hombre se encuentra efectivamente comprendido todo aquello que el hombre debe ser. Las argumentaciones morales de la tradición clásica, en sus versiones griegas o medievales, comprenden un concepto funcional central, el concepto de hombre entendido como poseedor de una naturaleza específica y de un propósito vital o función esencial propia (MacIntyre, 1987: 82-83).
} 
en su concepción del florecimiento humano y fracasan al realizarse. Esta afirmación parecerá menos arbitraria una vez que pueda reconocerse que la posición aristotélica no implica una forma unívoca de realización humana. La perspectiva aristotélica da lugar a una gran variedad de formas mediante las cuales los seres humanos pueden actuar bien y vivir bien. He aquí, nuevamente, un tópico ya entrevisto en Tras la virtud:

\begin{abstract}
... lo que concretamente sea vivir la vida buena varia con las circunstancias, incluso aunque no cambie la concepción de la vida buena y permanezca igual el conjunto de virtudes encarnado en la vida humana. La vida buena para un ateniense del siglo $\mathrm{V}$ no será, por lo general, lo mismo que para una monja medieval o un granjero del siglo XVII (MacIntyre, 1987: 271).
\end{abstract}

El autor se expresa en términos enteramente análogos en su último libro:

\begin{abstract}
Una cosa es lo que era realizarse en tanto ser humano para un ateniense de la época de Aristóteles, y otra muy distinta lo que era para un granjero irlandés o un mercader japonés del siglo XVIII o un dirigente de sindicato inglés del siglo siguiente. Esta variedad de vías para la realización no la reconoció siempre el propio Aristóteles, pero es crucial dejar constancia, para describir, como ahora intento, «lo bueno» y el bien en términos neoaristotélicos, de que hay efectivamente diversas formas de realizarse, y todavía más modos en los que puede fracasarse en ese empeño (MacIntyre, 2017: 67-68).
\end{abstract}

Como señala la primera de las dos citas precedentes, la concepción de la vida buena no varía con las circunstancias, pero sí cambia lo que sea, concretamente, vivir la vida buena, es decir, hay una "fórmula" aristotélica del florecimiento y un modo diverso de encarnarlo. La tesis de Aristóteles sostiene que las personas que están realizadas o en camino de estarlo poseen aquellos atributos de la mente y el carácter que les permiten, a través de sus relaciones con otros, desarrollar sus capacidades específicas (las propias de su biología metafísica) y, de este modo, alcanzar los auténticos bienes que completan y perfeccionan sus vidas. En otros términos: solo por medio de las virtudes, y en tanto que ellas se "adhieren" a nuestras facultades y nos permiten desarrollarlas de manera excelente, pueden alcanzarse los verdaderos bienes humanos y, en consecuencia, el florecimiento. Sin embargo -afirma MacIntyre-, esta escueta fórmula "deja en la sombra" lo diversas que pueden ser, en diferentes circunstancias y en el seno de diferentes órdenes culturales, las vidas que ejemplifican esto (MacIntyre, 2017: 67-68). Por lo tanto:

... en diferentes lugares y tiempos, lo que constituye de hecho una misma visión subyacente sobre la realización humana puede expresarse mediante juicios en apariencia muy distintos e incompatibles sobre lo que es bueno que esos agentes particulares en esas particulares circunstancias sean, hagan o tengan (MacIntyre, 2017: 68).

A partir de esto, no es sorprendente, por tanto, que aquello en lo que consiste el florecimiento humano, en estas o aquellas circunstancias concretas, tenga que ser descubierto, no es algo que se encuentra perfectamente caracterizado desde el comienzo.

En el transcurso de la búsqueda y solo mediante encuentros y enfrentamientos con los varios riesgos, peligros, tentaciones y distracciones que proporcionan a cualquier búsqueda sus incidentes y episodios, se entenderá al fin la meta de la búsqueda (MacIntyre, 1987: 270).

A su vez, este descubrimiento de cómo ha de encarnarse, aquí y ahora, es frecuentemente resultado del disenso; en ocasiones, de un debate entre personas corrientes que discuten -por ejemplo, un matrimonio frente a una decisión que puede cambiar sus vidas- sobre cuál es el siguiente paso que han de dar para conseguir su bien común. Otras veces, el conflicto se da entre teóricos que reflexionan sobre las prácticas que atañen a esas mismas personas corrientes Pero importa ahora destacar la convicción macintyreana que subyace a toda la argumentación precedente: el hecho de que, de vez en cuando, se multipliquen las discrepancias sobre qué es para este individuo o grupo florecer, no proporciona en modo alguno una razón para rechazar la concepción neoaristotélica sobre la realización humana. Los neoaristotélicos tenemos argumentos para esgrimir frente a las voces emotivistas que aspiran a imponerse en este tiempo (MacIntyre, 2017: 68). 


\section{Palabras finales}

La contribución que he sugerido no tiene otro mérito que el de arrojar luz sobre la hermenéutica macintyreana en torno a las nociones de lo bueno y el bien. Como se puso de manifiesto desde el comienzo de la exposición, los conflictos sobre lo bueno atraviesan los diversos ámbitos de nuestra cultura: las personas corrientes y los teóricos se embarcan en interminables disputas acerca de este tema y es frecuente que todos esos intercambios nos conduzcan hacia un impasse, es decir, hacia un cierto callejón sin salida tanto comunitario como filosófico. Los conflictos comunitarios suelen expresarse en rupturas que son frecuentemente dolorosas; los debates teóricos suelen constituirse en diálogos de sordos donde cada una de las partes solo se escucha a sí misma y encuentra una suerte de autocomplacencia hedonista en el oír la propia cadencia discursiva.

Las dos posiciones teóricas presentadas en este artículo tienen diverso grado de aceptación entre las personas corrientes. En pocos años se cumplirán cuatro décadas del "nacimiento" de Tras la Virtud donde ya MacIntyre afirmaba que hoy la mayoría de la gente piensa, habla y actúa en gran medida como si el emotivismo (expresivismo) fuese verdadero (MacIntyre, 1987: 39). En cambio, la posición aristotélica que supone una teoría objetiva de los bienes y del florecimiento es cada vez más marginal en nuestro tiempo. Se trata de una concepción que, sin negar la particularidad $-\mathrm{y}$ partiendo de ellaprocura alcanzar la universalidad de un modo de comprender la buena vida humana que trascienda los tiempos y las culturas (aunque, como quedó claro al final del apartado precedente, pueda encarnarse a través de una riqueza plural de manifestaciones). No sin razón MacIntyre es un pensador contracultura, un crítico de la modernidad tardía, no solo por el tipo de desigualdades que ella genera desde una perspectiva socioeconómica, sino también por el tipo de subjetividad que, a partir de sus estructuras, se contribuye a formar (MacIntyre, 2017: 230).

Demás está decir que comparto la posición de MacIntyre, una postura que, sin ser tradicionalista, se sustenta en una tradición; una posición que, sin ser conservadora, procura conservar las riquezas del pasado junto con una concepción racional de la autoridad. Hay notas propias del florecimiento: no se puede florecer sin virtudes y yendo en contra de las inclinaciones propias de nuestra naturaleza; no se puede florecer sin verdadera vida comunitaria y sin desarrollar la dimensión teorética de nuestra existencia. Claro está, no resulta sencillo (ni gratuito) afirmar públicamente estas convicciones; no es fácil ir en contra de lo políticamente correcto y plantarse frente a una cultura que rechaza de plano a todo aquel que afirme públicamente la posibilidad de alcanzar una teoría verdadera y objetiva, tanto de los bienes humanos como de su ordenación jerárquica. Por este motivo me parece imprescindible recuperar la argumentación macintyreana a favor de un neoaristotelismo que nos invite a entusiasmarnos nuevamente con la vida virtuosa. ¿Acaso la realidad en su conjunto no clama a gritos que el individualismo liberal y secularizante nos ha sumergido en una auténtica noche oscura de la civilización? Los bárbaros continúan gobernando, pero San Benito aun no reverdece (MacIntyre, 1987: 322).

\section{Referencias bibliográficas}

Amengual, G. (2016). Antropología Filosófica. BAC. Madrid.

Berti, E. (2012). El pensamiento político de Aristóteles. Gredos. Madrid.

MacIntyre, A. (1987). Tras la Virtud. Crítica. Barcelona.

MacIntyre, A. (1992). Tres versiones rivales de la ética. Enciclopedia, genealogía y tradición. Rialp. Madrid.

MacIntyre, A. (2001). Animales racionales y dependientes. Por qué los seres humanos necesitamos las virtudes. Paidós. Barcelona. 
MacIntyre, A. (2017). Ética en los conflictos de la Modernidad. Sobre el deseo, el razonamiento práctico y la narrativa. Rialp. Madrid.

Maritain, J. (1982). Los derechos del hombre y la ley natural. Leviatán. Buenos Aires.

Nussbaum, M. (2008). Paisajes del pensamiento. La inteligencia de las emociones. Paidós. Barcelona.

Rodríguez Luño, A. (2004). Ética general. Eunsa. Navarra. 